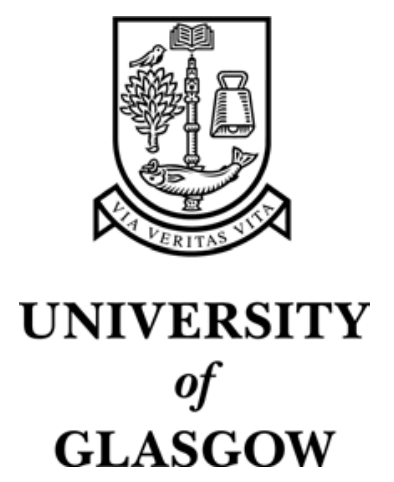

Pollock, M.J. (2002) Introduction of CAA into a mathematics course for technology students to address a change in curriculum requirements.

International Journal of Technology and Design Education 12(3):249270.

http://eprints.gla.ac.uk/archive/00002099/ 


\title{
Introduction of CAA into a mathematics course for technology students to address a change in curriculum requirements
}

\author{
Dr Margaret J Pollock \\ Robert Clark Centre for Technological Education \\ 66 Oakfield Avenue \\ University of Glasgow \\ Glasgow \\ Scotland \\ G12 8LS
}

\begin{abstract}
The mathematical requirements for engineering, science and technology students has been debated for many years and concern has been expressed about the mathematical preparedness of students entering higher education. This paper considers a mathematics course that has been specifically designed to address some of these issues for technology education students. It briefly chronicles the changes that have taken place over its lifetime and evaluates the introduction of Computer Assisted Assessment (CAA) into a course already being delivered using Computer Aided Learning (CAL).
\end{abstract}

Benefits of CAA can be categorised into four main areas.

1. Educational - achieved by setting short, topic related, assessments, each of which has to be passed, thereby increasing curriculum coverage.

2. Students - by allowing them to complete assessments at their own pace removing the stress of the final examination.

3. Financial - increased income to the institution, by broadening access to the course. Improved retention rate due to self-paced learning.

4. Time - staff no longer required to set and mark exams.

Most students preferred this method of assessment to traditional exams, because it increased confidence and reduced stress levels. Self-paced working, however, resulted in a minority of students not completing the tests by the deadline.

\section{Keywords:}

Computer Assisted Assessment, Computer Aided Learning, mathematical capability, curriculum coverage, income, increasing access, mathematics, self-paced learning, retention rate.

\section{INTRODUCTION}

There has been a continuing debate since the mid 1980s and particularly during the last decade about the mathematical capability and/or preparedness of students entering higher education courses. Larcombe (1998) summarises many of the changes that have taken place over the last thirty years which have culminated in the crisis that engineering and technology courses are now facing as new cohorts of students no longer display the mathematical knowledge and capability 
that were once taken for granted. Mathematicians within higher education, who are intrinsically involved in providing the mathematical education for scientists, engineers and technologists, were so concerned that the Council of the London Mathematical Society established a working group to report on the state of school mathematics and make suggestions for improving matters. The report notes that, 'The working group's primary finding is that the United Kingdom faces extremely serious problems relating to the supply and mathematical preparation of entrants to university courses in mathematics, science, engineering and technology' (LMS 1995). There is also evidence that students entering with vocational qualifications are even less prepared than school leavers (Lawson 2000). Most of the problems reported refer particularly to students with 'A' level qualifications, who have been through the national curriculum in England and Wales. The problem in Scotland does not appear to be quite as acute, but there is much anecdotal evidence to support the assertion that students are less prepared in basic mathematical skills than ten or fifteen years ago (Cook 1997). This is reinforced by the Report of the Fourth Survey of Mathematics (Robertson et al. 1994; Robertson 1996) as part of the Assessment of Achievement Programme (Scotland), where a drop in performance in some of the basic number handling skills (such as decimals and fractions) is indicated between 1991 and 1994. The survey looks at primaries 4 and 7 and secondary 2 pupils and the decrease in performance is apparent at all three stages.

This paper does not intend to discuss the reasons for the decline in mathematical capability of university entrants to science, engineering and technology courses, many of which have been expounded by the London Mathematical Society (1995), but suggests one way of addressing the problem.

Cox (1997) at the IEE Colloquium on Teaching of Mathematics considers the challenge that staff and students face during the transition to first year undergraduate programmes and makes a few proposals for dealing with it, some of which are already being introduced by universities. The Engineering Council (2000) also reports on what some universities have implemented and tenders a number of recommendations to alleviate the problem in both the short and long term. Loughborough University, for example, has set up a Mathematics Learning Support Centre (Croft 2002), where students can drop in and use the facility at any time. One of its stated aims is 'to help students in the earlier stages of their studies who might benefit from resources and tuition over and above that normally provided as part of their programme'. The University of Glamorgan is looking at ways of placing less emphasis on mathematics and more emphasis on engineering in the earlier years (Otung 2001) so that students are not discouraged by the excessive mathematical content. Many universities such as Keele and Leeds use diagnostic testing to identify students' weaknesses and offer extra classes and support or even stream their students. The problem is not restricted to the UK as Monash University in Australia also plans to change its course structure to make mathematics more palatable to engineering students (Brisk, 1998).

Technology students do not need to study mathematics to the same depth as engineering undergraduates, but the ability to apply basic mathematical concepts within subjects such as electronics and mechanics, in other words the use of mathematics as a tool, needs to be accurate and automatic. We have also found that the students who start the degree come with a wide range of mathematical capabilities and skills. We addressed this problem initially by the introduction of Computer Aided Learning (CAL) for material delivery, to aid independent 
learning and allow students to work at their own pace between exams. Latterly Computer Aided Assessment (CAA) has been introduced to assess the learning.

\section{THE DEGREE PROGRAMME}

The Bachelor of Technological Education (BTechEd) degree is a four year BEd degree designed to educate future teachers of Craft and Design, Graphic Communication and Technological Studies in Scottish schools (Doughty 2002), the Scottish equivalent of the English Craft, Design and Technology curriculum. We accept a variety of applicants, from students having just left school, many of whom have studied at least one or two of the three subjects they will have to teach, to mature students who have completed an Access into Higher Education course. We also take students with HNCs and HNDs in related subjects such as Design, Electronics and Mechanics. A vast range of abilities is required to teach the three school subjects up to Higher and Advanced Higher levels and many applicants including school leavers and mature students have a wide variety of skills to offer the teaching profession. Lack of mathematical competences will really only hinder them in one of the subject areas they have to teach, namely Technological Studies, although Graphic Communication and Craft and Design use mathematical skills to a more limited extent (Evens and McCormick 1998; McCormick and Murphy 1998). By allowing a student to join the course with expertise in areas such as design, craft or drawing skills, enables them to free some of their time to learn and master techniques in other subjects where they are less able, such as mathematics.

When the degree was introduced, fifteen years ago, the students were being prepared to teach two school subjects, Technological Studies and Craft and Design. The more significant of the two was Technological Studies as its introduction represented a substantial change in curriculum content for a school's technical department. Craft and Design at that time still concentrated mainly on craft skills with the introduction of a little design. The old school subject of Technical Drawing was to be phased out and subsumed into the curriculum of these two new subjects.

A stand made by some of the technical teachers in schools in the early 1990s meant that this never happened and Technical Drawing was broadened to include sketching, layout drawings, rendering and the use of computers for techniques such as CAD and thus developed into a third school subject, Graphic Communication. Craft and Design was also revised to increase the importance of design and reduce the prominence of hand skills. This has resulted in a change in emphasis in the technology curriculum in schools over the intervening years with a reduction in students opting to take Higher Technological Studies by 9\% from 1995 (SAB 1995) to 2000 (SQA 2000) whereas Higher Graphic Communication and Higher Craft and Design have shown an increase in uptake by $44 \%$ and $32 \%$ respectively. In real terms this means that although the figures for students opting to take Higher Graphic Communication and Higher Craft and Design are roughly equal, Technological Studies now represents less than one sixth of the pupil intake into Scottish Higher Grade Examinations within technology departments resulting in some departments no longer offering the subject. This has also meant a change in the type of pupils being attracted to studying the technical subjects particularly the gender balance. The number of girls studying Higher Graphic Communication increased from $17 \%$ to $25 \%$ of the total between 1995 and 2000 while Higher Craft and Design, with its revised syllabus requiring a greater emphasis on design, increased from $19 \%$ to $30 \%$ over a similar period. In Technological Studies, however, only $6 \%$ of its uptake are girls and this has not changed. A new subject, Advanced Craft 
Skills, has also been introduced into the school syllabus in the last year, thus precipitating a drift back to where the technology departments were 15 years ago. The change in emphasis within the technology departments away from Technological Studies to more design and drawing orientated subjects has resulted in a rise in applications from girls who want to teach these school subjects. The number of girls joining the course in the first year has doubled from an average of 4.7 girls per year over the first ten years of the course increasing to an average of 9.4 girls per year over the last five years.

Despite all the changes that have taken place in the technology departments in schools we are still required to prepare our students to teach all the three subjects Technological Studies, Craft and Design and Graphic Communication and also Advanced Craft Skills.

Until relatively recently we have insisted on a pass in Higher Mathematics as an entrance qualification for the degree, to enable students to cope with the technology subjects. Over the last three or four years, however, this requirement has been relaxed to encourage students with broader backgrounds to join the course. This has been monitored quite carefully to see how these students coped with the maths course and found that most students lacking maths qualifications were sufficiently motivated to develop the skills needed by using the computer aided learning package and have finally decided to drop mathematics as a prerequisite entrance qualification.

The degree is a concurrent teaching degree where the students learn the subject content whilst also developing their teaching skills. On the course they have to master design and modelling skills, woodworking and metalworking skills (craft skills), drawing skills, IT skills and all associated subject content. They also learn technology subjects, including electronics, mechanics, structures and materials, and it is mostly for the understanding and interpretation of these latter subjects that students need a sound grounding in mathematics.

As most of the students are going to become teachers they are exposed to as many different teaching and assessment techniques as possible, with the particular aim of making them responsible for their own learning. Learning and teaching methods employed include classroom discussions; e-mail conferencing; drawing; laboratories; lectures; seminars; tutor-supported CAL; tutorials; visits; workshops; student centred learning; flexible learning; individual and group projects; project based learning; peer teaching; problem solving; resource based learning; student produced CAL. Assessment varies greatly in nature but includes written examinations; essays; reports; oral presentations; designing and producing artefacts; self and peer assessment; CAA.

The remainder of this paper describes how the development of the mathematics course and the introduction of CAA have allowed students with wide varieties of skills to join the degree and become technology teachers.

\section{THE MATHEMATICS CURRICULUM Historical development of the mathematics course}

In 1994 the Mathematics course had been running for 7 years, taught over three years totalling 150 hours of lectures. The three year course was gradually shortened to one year, and during this process, all content was stripped out which was not necessary for further study of the technology subjects. This was in line with cutting course content in other subject areas to reduce the general 
overload of the degree, which was now having to include subject content for three school subjects instead of the two that were originally envisaged, whilst also covering the material in sufficient depth to offer a credible Honours degree.

To aid the course changes and also allow students to work at their own pace between examinations Computer Aided Learning (CAL) was introduced into the course in 1994 as the main delivery medium for course content, but conventional examinations were retained until 1999. The programme CALMAT was used (Computer Aided Learning in Mathematics produced by Glasgow Caledonian University) (Cook 1994; Cook and Hornby1995; Tabor 1993) with supplementary textbooks and worksheets (Doughty et al. 1997).

The mathematics class was run in one block of three hours per week over 25 weeks. It was more convenient to book computer suites and employ tutors in these time denominations, and students were encouraged to take frequent breaks. In session 1994/95 there was no lecture or tutorial input and students were helped on an individual basis. This resulted in a pass rate of $81 \%$ (Pollock et al. 1996). As a consequence of the evaluation of the introduction of CAL, lecture/tutorials were introduced into the following sessions to run alongside the students work time and resulted in increasing the pass rate to an average of over $95 \%$ (taken over the next four years). This, however, meant slipping back to using lecture/tutorials as well as CAL and interfered with the students' ability to study at their own pace.

Students were encouraged to buy a copy of CALMAT and use it to assist with home study if they had access to a PC. When questioned it was noted that many students, particularly those, who were struggling with their maths, took up this option.

With the introduction of CAA in 1999, the class delivery changed back again to three-hour sessions on the computer with students getting individual help and no lecture/tutorial input (apart from the one topic for which there was no adequate CAL provision). They were again encouraged to take breaks if necessary. They were required to complete their assessments during the time-tabled hours before the end of the academic year, but they could once more work at their own pace.

\section{Aims of the mathematics course}

Within the degree course, there is no intrinsic requirement for mathematical knowledge and skills. Mathematics is included in the syllabus with the particular aims of facilitating the learning of the technology subjects and also making sure that the students can apply the mathematical concepts (particularly basic algebraic and arithmetical skills) correctly when teaching the technology subjects in schools.

To ensure that students are confident enough with their mathematical skills when teaching technology to pupils in the classroom, the necessity for making the students complete and be assessed on the whole mathematics curriculum became apparent. One of the ways to achieve that was to adapt the assessment so that the students were assessed in all relevant areas of the curriculum. 
Before adoption of CAA was even considered, a problem with coverage of material using traditional examinations had already been identified and a need to revise the assessment system had been implied. In 1998, when paper tests and examinations were still in use it was recognised that some sampling of course content was inevitable and estimated coverage varied with student grade. Considering a pass mark of $40 \%$ the maximum understanding of what was being tested was presumed to be $40 \%$ and may well be considerably less. It was felt that this form of assessment did not suit the purpose of the course since students could avoid topics they found difficult or were unsure of. It was obvious that assessment which highlighted understanding of only a small fraction of the mathematics curriculum was inadequate as a measure of whether students were well enough prepared to use it for teaching some of the subject content in schools e.g. electronics or mechanics.

Increasing the pass mark of the exam to $100 \%$ to ensure complete coverage of all the topics would be difficult to justify and impossible to attain. In other contexts, it would be quite acceptable for students to be asked to only demonstrate understanding of some of the curriculum covered. In this context, however, reasonable understanding of the whole curriculum is important and one method of achieving this coverage is to insist that the students pass all of a series of short assessments, each one of which is related to a different topic.

\section{Evolution of the course assessment procedure}

Before the introduction of CAA in session 1999/2000, CAL was embedded into the course, but the assessment remained as traditional examinations. There was one class exam before Christmas, one class exam after Easter, a degree exam in June and an opportunity to resit in August. Students whose aggregate score for the two class exams were $60 \%$ or above were exempt the degree exam. Students who failed the degree exam were offered a further resit.

To overcome the problem of coverage, the year before the introduction of CAA (session 98/99) the students were given tutorial sheets on a different topic each week (as well as using CALMAT) and when they felt they understood the topic, they completed a multiple choice test on that topic. Over the previous four years since the introduction of CAL an average of $50 \%$ of the students gained a score of $60 \%$ or more either by exemption or in the degree exam. After the introduction of continuous testing (even though it was only formative) $74 \%$ of the students gained a final score of $60 \%$ or more. The continuous testing appeared to have a positive effect on the overall exam score for a greater number of students and thus, hopefully, increased the understanding of the subject content on the course. It was, however, very labour intensive and time consuming for the lecturer.

As a consequence of the positive results obtained that year, and in consultation with the external examiner, a decision was made to change the assessment system so that the students could sit 10 short tests, each concentrating on a separate topic, instead of the traditional exams. The proposal was submitted to the institution's quality assurance procedure and approved. The students are now required to complete ten short assessments, and have to reach a level of at least $40 \%$ on each assessment with an aggregate score of at least $50 \%$ before being regarded has having completed and passed the course. At this stage it was recognised that this decision was likely to significantly increase staff time spent on assessment. This perception coupled with the discovery that the CALMAT software, to which we were already committed, had associated CAA software 
led to the consideration of CAA as a solution. In the following session, ten short tests were administered. Nine of these used CAA and one was a conventional paper test on statistics, as CALMAT did not cover the subject as required. The end-of-year examination was abandoned.

\section{Software adopted}

The Computer Assisted Assessment programme adopted for the assessment is called TASMAT (Tutorial and Assessment in Mathematics) and was produced by the developers of the CAL Programme CALMAT that we have been using for the past seven years. TASMAT is directly linked to the CAL package and any number of tests can be produced using TASMAT's bank of questions and the tests can be linked back to modules in the teaching programme CALMAT (2002; Booth 1998).

Each test has a total of 10 questions and for each of the 10 questions a maximum of 8 questions may be allotted. So each test of 10 questions can be made up from a bank of 80 questions all related to the same topic. The numbers within the questions themselves are also randomly chosen. All the choice and randomisation reduces the possibility of cheating because no two students will sit exactly the same test. Students may try each test first as a tutorial (as many times as they like) and the final result is not recorded. When they feel confident enough to sit the test as an assessment, they must inform the tutor. They are only allowed one attempt and the final result is recorded. It is obvious to the tutor whether a student is doing a tutorial or sitting a test as the background colour of the programme changes from green to blue between a tutorial and test.

A screen shot showing an example question from Test4, with solution to help the student, is shown in Figure1. Students can be given hints or whole solutions as required. During an actual assessment this facility is disabled.

Fig. 1 - Screen shot of TASMAT

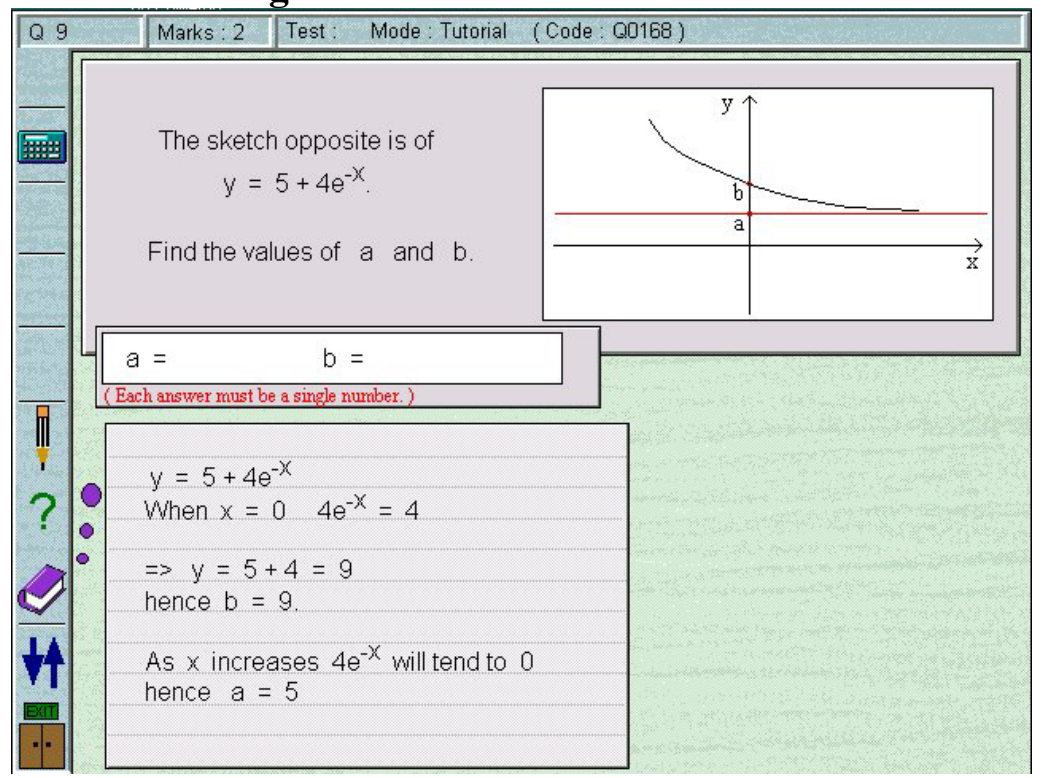

For the purpose of this course a set of nine tests (each having 10 questions) were designed with each one testing a particular topic (Pollock et al. 2000). The course also has a tenth paper test on a topic for which there are no suitable CAL teaching modules or CAA questions at present. Two 
tutorials/lectures are run to introduce the topic and the paper test is administered several weeks later. No special time is set aside for the students to sit an assessment, as they are to be completed during the time-tabled hours, at the students' own pace (apart from the paper test which is given at the end of the year).

\section{The Tests}

The following paragraphs show what is covered by the tests. These were the basic skills considered by all staff to be the most important for the students to become mathematically fluent. For any extra topics (for example, complex numbers) an agreement was reached with staff requiring them that they would be dealt with in class as required. As can be seen the course covers the learning and reinforcement of basic mathematical skills.

Tests $1 \& 2$ - Revision of arithmetic, including integers; factors and multiples; fractions; decimals; rounding and estimation; percentages; ratio and proportion; standard form; squares and square roots; variation.

Test 3 - Revision of algebra including introduction of variables; like and unlike terms; indices; algebraic expressions; algebraic laws; factorisation; linear equations; changing the subject of the formula; algebraic fractions; simultaneous equations; quadratic equations.

Test 4 - Further algebra including review of graphs and their equations; roots and indices; functions and their graphs; further quadratic equations; systems of equations and factorisation; remainder theorem; factor theorem; related and inverse function; completing the square.

Test 5 - Revision of geometry including angles and triangles; straight lines; circles; areas and volumes; radians; straight line laws including log graphs.

Test 6 - Revision of trigonometry including angles, lines, triangles; parallel and perpendicular lines; pythagoras' theorem; similar figures; right triangles; trigonometric functions and their graphs.

Test 7 - Further trigonometry including radian measure; trigonometric graphs; addition formulae; further trig relationships; trig equations and three dimensional trig.

Test 8 - Exponential Functions and Logarithms including exponential and log graphs; exponential functions; logarithms, laws and graphs; solving exponential equations; growth and decay.

Test 9 - Calculus including differentiation; the chain rule; maxima and minima; integration; differentiation and integration of trig functions; definite integral; area under curve; derivatives of $\log$ and exponential function.

Test 10 - Statistics including data collection, categorisation and display; mean, median and mode; normal distributions; variance and standard deviation.

\section{TIME COMPARISONS}


It was realised very early on that there was going to be an increase in staff time required to run the assessments when the change was introduced. There follows a comparison of the time taken to run the traditional assessment, an estimate of the time it would take to run the short tests without using CAA, and the time taken to introduce CAA. This shows that by setting ten tests and running them as examinations in the traditional manner, it would probably have taken about twice the time taken to set and run the present system of examinations, but the introduction of CAA to run the tests has actually resulted in more than halving the time taken for the assessments.

\section{Time taken for traditional assessment}

The time taken to assess the traditional way, for 30 students, was estimated to be about 60 hours and is dependent on the number of students doing the course - see Table I. Exam paper preparation time always included preparation of solutions, word processing and photocopying for class exams and also preparation for printing for the degree exams.

The first class exam was a mixture of multiple choice questions (MCQs) and short standard questions (40 MCQs plus 10 short questions). The second class exam was a standard examination with 10 long questions, each assessing a different topic. Students had to attempt all 10 questions. The main degree exams followed the same format as the second class exam, but the assumption was made that about $50 \%$ of students gained an exemption so only the remainder sat the degree exam. Again the resit exam followed the same pattern as the main degree exam and the assumption now was that only $10 \%$ of students would need resits . Table I shows time estimates for each activity. Time taken to assess about 30 students is estimated to be about 60 hours (58hrs).

Table I - Time estimates for each activity for traditional assessment.

\begin{tabular}{|l|l|c|c|c|c|c|}
\hline & Class Exam & Class Exam 2 & $\begin{array}{c}\text { Degree Exam } \\
\mathbf{1 5 0 \%} \text { of } \\
\text { students) }\end{array}$ & $\begin{array}{c}\text { Resit Exam } \\
\mathbf{1 0 \%} \text { of } \\
\text { students) }\end{array}$ & Totals \\
\hline Fixed time & $\begin{array}{l}\text { Preparation } \\
\text { time }\end{array}$ & $10 \mathrm{hrs}$ & $5 \mathrm{hrs}$ & $5 \mathrm{hrs}$ & $5 \mathrm{hrs}$ & $25 \mathrm{hrs}$ \\
\hline Fixed time & $\begin{array}{l}\text { Invigilation } \\
\text { time }\end{array}$ & $3 \mathrm{hrs}$ & $3 \mathrm{hrs}$ & $3 \mathrm{hrs}$ & $3 \mathrm{hrs}$ & $12 \mathrm{hrs}$ \\
\hline Fixed time & $\begin{array}{l}\text { Marking } \\
\text { time per } \\
\text { student }\end{array}$ & $\begin{array}{c}\text { approx } 10 \\
\text { mins }\end{array}$ & $\begin{array}{c}\text { approx } 20 \\
\text { mins }\end{array}$ & $\begin{array}{c}\text { approx } 20 \\
\text { mins }\end{array}$ & $\begin{array}{c}\text { approx } 20 \\
\text { mins }\end{array}$ & \\
\hline Variable time & $\mathbf{2 0}$ students & $3.3 \mathrm{hrs}$ & $6.7 \mathrm{hrs}$ & $3.3 \mathrm{hrs}$ & $0.7 \mathrm{hrs}$ & $14 \mathrm{hrs}$ \\
\hline Variable time & $\mathbf{3 0}$ students & $5 \mathrm{hrs}$ & $10 \mathrm{hrs}$ & $5 \mathrm{hrs}$ & $1 \mathrm{hrs}$ & $21 \mathrm{hrs}$ \\
\hline Variable time & $\mathbf{4 0}$ students & $6.7 \mathrm{hrs}$ & $13.3 \mathrm{hrs}$ & $6.7 \mathrm{hrs}$ & $1.3 \mathrm{hrs}$ & $28 \mathrm{hrs}$ \\
\hline Totals & $\mathbf{2 0}$ students & $16.3 \mathrm{hrs}$ & $14.7 \mathrm{hrs}$ & $11.3 \mathrm{hrs}$ & $8.7 \mathrm{hrs}$ & $51 \mathrm{hrs}$ \\
\hline Totals & $\mathbf{3 0}$ students & $18 \mathrm{hrs}$ & $18 \mathrm{hrs}$ & $13 \mathrm{hrs}$ & $9 \mathrm{hrs}$ & $\mathbf{5 8 h r s}$ \\
\hline Totals & $\mathbf{4 0}$ students & $19.7 \mathrm{hrs}$ & $21.3 \mathrm{hrs}$ & $14.7 \mathrm{hrs}$ & $10.3 \mathrm{hrs}$ & $65 \mathrm{hrs}$ \\
\hline
\end{tabular}

\section{Time taken to assess 10 short paper tests}

The new assessment scheme would have introduced ten short paper tests each on a different topic. A short paper test was estimated to take less time than preparing an examination. Table II shows the estimated preparation and marking for the new paper tests to be about 110 hours for 30 students. This would have been approximately double the commitment of traditional exam assessment. 
Table II - Estimated times for administering the new assessment as paper tests.

\begin{tabular}{|l|l|c|c|}
\hline & & Time taken for short test & Total time for 10 tests \\
\hline Fixed time & Preparation time & $2 \mathrm{hrs}$ & $20 \mathrm{hrs}$ \\
\hline Fixed time & Invigilation time & $1.5 \mathrm{hrs}$ & $15 \mathrm{hrs}$ \\
\hline Variable time & $\begin{array}{l}\text { Marking time per } \\
\text { student }\end{array}$ & approx $15 \mathrm{mins}$ & \\
\hline Variable time & $\mathbf{2 0}$ students & $5 \mathrm{hrs}$ & $50 \mathrm{hrs}$ \\
\hline Variable time & $\mathbf{3 0}$ students & $7.5 \mathrm{hrs}$ & $75 \mathrm{hrs}$ \\
\hline Variable time & $\mathbf{4 0}$ students & $10 \mathrm{hrs}$ & $100 \mathrm{hrs}$ \\
\hline Totals & $\mathbf{2 0}$ students & $8.5 \mathrm{hrs}$ & $85 \mathrm{hrs}$ \\
\hline Totals & $\mathbf{3 0}$ students & $11 \mathrm{hrs}$ & $\mathbf{1 1 0 h r s}$ \\
\hline Totals & $\mathbf{4 0}$ students & $13.5 \mathrm{hrs}$ & $135 \mathrm{hrs}$ \\
\hline
\end{tabular}

\section{Time taken for assessment using CAA}

Using TASMAT, one academic had to become familiar with the TASMAT system, check how the questions related to required topics in CALMAT, set up 9 tests and try the questions herself. In the first year, this took approximately 20 hours and in the following academic session (2000/2001) the process took about 5-10 hours - which is expected to be typical for subsequent years. The whole course, including the assessments, was run within the time-tabled class hours, apart from the paper test, which took about 10 hours to set, invigilate and mark.

Unexpected difficulties in the first year took approximately an additional 10 hours of staff time, but this occurred during time-tabled class time. These difficulties included sorting out computer crashes that occurred during tests and checking students work so that using CAA did not disadvantage them. General control of record keeping etc. takes about another 5 hours in total.

Therefore total time required for the introduction and running of the CAA was about 35-40 hours, not including the paper test, less time than spent on traditional assessment and about one third of the time that would have been required to introduce the new method of assessment on paper.

Staff time required to control the continuing use of CAA is likely to reduce further to about 20-30 hours a year, as familiarity with the system increases.

\section{EVALUATION}

When any innovation or change is introduced into a course, it makes sense to evaluate it with more care than usual. The Robert Clark Centre, where the staff and students mentioned in this paper were based, has an enviable reputation for the evaluation of learning (RCC, 2002) and though evaluation of these new assessment arrangements was more extensive than usual, an exhaustive independent evaluation was not used. The consequences of introducing CAA were investigated under the five main headings of:-

1. the educational objectives,

2. the student feedback and responses,

3. the financial considerations,

4. the time implications, and

5. the disadvantages. 
Several major benefits emerged relating to the first four of the headings that were evaluated and are summarised below.

- An educational benefit in that students are now assessed on each topic and must pass each assessment so that all the gaps in their skills and knowledge are filled. This was the primary reason for the assessment change.

- A benefit to the students by allowing them to tackle the assessments at their own pace thus increasing their confidence in the subject and reducing their stress by not having to sit an end-of-year examination. They also get immediate feedback on their progress.

- A financial benefit to the institution by increasing access and improving retention rate. .

- A reduction in time spent by the lecturer on assessment allowing them to spend more time assisting students individually and also use their time more productively.

A discussion of the benefits and disadvantages of introducing CAA will follow in more detail under each of the original headings.

\section{Educational objectives}

The most important educational benefit and principal reason for introducing CAA has been the ability to set a number of short assessments which are topic related thus making the students engage in every topic and not miss what they find difficult or do not like. They are required to pass each topic. This is more difficult to do with the traditional exam format unless a test is set for each topic, thus increasing setting and marking time quite dramatically as already discussed.

An unforeseen educational benefit of assessing this way has been to allow the students to sit the tests when they feel ready in class time and thereby allowing them to work at their own pace. They can try the tutorials as many times as they like, thus assisting them with their learning and the development of their mathematical skills. The assessment is directly linked to their learning.

\section{Student feedback and responses}

This type of assessment was unfamiliar to the students and it was very important to gather as much information as possible about their reactions to it. Supplementary to the usual combination of reports from lecturers, student evaluation forms and a staff-student committee, students were issued with a questionnaire to allow them to express their thoughts about this method of assessment, especially to allow them to compare it with classical examinations with which they are all familiar. These free responses are illuminating and are reported in some detail. Of the 27 students on the course in session 99/00 (two of whom were repeating from the previous year) 20 returned the questionnaire and of the 32 on the course in session 00/01 23 returned the questionnaire. Last session 16 (including both of the students who were repeating from the previous year) and this session 17 students preferred CAA to traditional exams. A selection of student responses to questions follow. Some apparently puzzling responses show up the confusion in the students' minds between using the computer to help them learn the mathematics and using it for sitting the assessments. All students comments are in itallics.

\section{Question:- 'If you prefer traditional exams please give your reasons'}

Some of the responses from the students who said they preferred traditional exams were:-

\section{'Traditional exams allow proper exam conditions to be held.'}


'You can work for them at home.'

'I think computers are too limited, there was problems on input. Don't like operating a computer at same time as doing maths.'

'On the computer I tended to forget how to go about the questions after a lack of revision. This does not tend to happen when revising for an exam, but I believe there is an awful lot of material in the Higher Maths course.'

'Feel more confident with trad. But don't mind TASMAT really.'

Comment: Three students had problems with the fact that the computer only marked the final answer, despite the fact that this was addressed:-

'The points system is totally based on the final answer with the computers and not on the actual method of how you gained the final answer.'

'Given marks for working, computer system not user friendly.'

'With a computer you have to write down working, answers etc. in case it crashes.'

Comment: Two puzzling responses on assessment really referred to the teaching style i.e. the CAL package:-

'Traditional teaching with textbook reference. You can't ask a computer questions its hard for the teacher to provide explanations due to the fact that everyone is at different stages and maybe their mind is not as focussed as it would be if the class as a whole were tackling the same topics.'

Comment: The above is not necessarily agreed with by the lecturer or tutor.

'Rather use textbooks because you will always have them, but the computer takes up too much time.'

Comment: Some students feel more comfortable with what they are used to and were finding the medium of delivery i.e. the computer a problem. They did not like that the computer only marked the final answer and not the working, despite the fact that they had to do the working in workbooks and it could be checked by staff if there was a problem with the computer or they disagreed with answer and the students were then given credit for their working, if it was correct.

\section{Question:- 'If you prefer the Computer Assisted Assessment please give your reasons'}

(Where a number of students in both years gave very similar responses, this is indicated in brackets)

'More organised, less pressure' (+19 students), 'able to work at own pace' $(+12$ students).

'Its simpler and much easier to use' (+6 students).

'Continual assessment is much less stressful than exams. Takes off a lot of pressure. It allows the student to study techniques with both CAL and books. Ifound it beneficial, as maths has never been my strong subject.' 
'Flexibility and can be done in separate sections instead of all in one go' $(+2$ students).

$>$ From one of the students who preferred traditional exams (who was not, therefore, invited to complete this section) - 'I don't mind this but don't have access to a computer at home.'

Comment: The preference from the students seems to be for working at their own pace, and reducing the stress of examinations. In session 99/00 all 20 students said they said they preferred to work at their own pace, but in session 00/01 3 students said they didn't.

\section{Question:- 'Do you prefer to work at your own pace?'}

Student who preferred traditional exams

'In that respect I suppose it releases the pressure' (+ 8 other students)

Students who preferred CAA

'Definitely'

'The best way to learn anything is at your own pace. A subject can be boring if the pace is slow and a fast pace can be complicated to understand.'

'Ability to cover problem areas in more depth frequently.'

'You don't miss anything as you go at your own speed' (+4 students).

Problem with completion highlighted:-

'Yes, although sometimes I allow too long on one topic.'

'However, there has to be guidelines so you don't fall too far behind.'

'Although it does encourage you to be lazy.'

Student who did not like going at own pace:-

'I like to be pushed with Maths.'

Comment: The recurring theme was that CAA reduces the stress on students. Three students, however, point out that they may spend too long on one area or that it could make them lazy.

Towards the end of the first year of using CAA time tabled classes had finished and some students realised that they still had assessments to finish, and there was a last minute rush. This was partly due to classes being missed because of two consecutive Bank Holiday Mondays. Extra time was made available for them to complete the assessments.

We were surprised no student commented on the usefulness of immediate feedback.

\section{Question:- 'Do you like being able to tackle the assessment as a tutorial before attempting the assessment?'}

'It lets you know if you're ready' (+ 11 students).

'Means more effective learning - find problem areas' (+1 student). 
'Similar to looking at past papers' (+5 students).

'This means you can have a go at a similar set of questions as what is in the assessment, so if any problems occur you can go over them again.'

'It gives you a chance to learn or recap on subjects you haven't attempted since school. They are well constructed and a lot of help when going on to do the assessment.'

Comment: All the students liked being able to tackle the assessments as tutorials beforehand. Those students who were struggling with maths spent quite a long time tackling the tutorials and learning from them. From the responses it is obvious that the students found this a most helpful way of learning.

This sort of testing reinforces the learning of skills because they can try many different questions on the same topic, and it is effectively no different to working through past exam papers. This also meant that staff no longer needed to run tutorials on the different topics, as the computer covered this.

Students were also asked if they had anything else to say about using CAA.

\section{Question:- 'Anything else you would like to say about this form of assessment?'}

'I believe that traditional exams can be used in the computer based assessment system.'

'I think I can perform better with this system of examination.'

'On the down side it has a kind of impersonal feel to it.'

'It works for me. Keep it going.'

'It enables mature students who are not very maths friendly to work at their own pace.'

'I don't really enjoy sitting at a computer and staring at the screen, but it was worth it.'

Comment: Despite the fact that some students did not like using this they appreciated its effectiveness.

>From the above comments of the students it is evident that they have found the way the maths course is delivered and assessed most useful and they appear to have a positive attitude towards this type of assessment and most students seemed to have benefited from it.

It should also be noted that in a recent staff/student course consultative committee, from session 01/02 the class representative reported back that, 'the students really liked the course being taught in this way, and could other courses also be taught like this'.

\section{Financial Considerations}

A relatively simple analysis of the financial benefits of this single innovation will be presented here. A more extensive discussion on the costs and benefits of using CAL and CAA but may be found in Doughty and Pollock (1998) and Pollock et al. (2000). The cost of establishing a 
computer suite to run the CAA are not considered here as a suite was already booked for delivering the CAL, and there is no extra requirement for computers.

Discussions about improved access and increased retention rate and consequential extra income received by the institution follow.

\section{Access}

Results from student feedback are so positive, especially from students who used to struggle with their maths, that the real cost benefit will come from improvements in recruiting. Greater flexibility can also be offered to those students who could make a positive contribution to teaching technology because of their background, but have been unable to obtain sufficient maths qualifications to enter the course. They have often gained good qualifications in other areas that will allow them to be given credit for prior learning and time saved could be used to catch up with their maths. This has already led to wider access on the course. Until recently we have had to turn students away because of their lack of maths qualifications and this has now enabled us to take students in this category. The amount of money the university receives for each student joining the course is approximately $£ 6000$ per year. Assuming this would allow three extra students to join the first year this would provide a cost benefit to the University of $£ 18000$ per year and over a four-year period $£ 72000$ altogether.

\section{Retention Rate}

It is of no use increasing access to a degree course only to loose students at the end of the first year. There is an inevitable loss of students during the first year due to wrong course choice, but losing students due to course failure can be addressed. Between 2 and 4 students used to fail the course each year and as a result often dropped out of the degree programme, resulting in a loss of income to the university of $£ 18000$ per student. If improving the assessment technique leads to a greater retention rate as expected, then the change is also worth about $£ 54000$ to the university in student fees over a three-year period, if 3 students are retained.

\section{Time implications}

Estimates of the relative staff times required for introducing CAA and/or a paper-based approach for administering 10 tests have already been presented. These indicate that the time taken for introducing a CAA approach in the first year to be of the order of a third of that for introducing the paper-based approach, with time reducing even further in subsequent years. The decision to adopt CAA was based initially on staff estimates of the time involved, after having already made the decision to change the assessment.

The lecture/tutorial sessions were no longer run or necessary because the students could tackle each test as a tutorial first before attempting it as an assessment. Each time the students try the test as a tutorial the questions will be shuffled and the numbers randomised, so they never have to answer exactly the same question twice. The tutor and lecturer spent their time giving individual help to the students, as they needed it.

The real benefit will emerge as we increase our intake without having to increase time spent on assessment, so there would also be cost benefits here. 


\section{Disadvantages of using CAA}

Allowing students to work at their own pace and thus sitting assessments when they are ready could make it possible for them to cheat. This is made as difficult as possible in this situation by each student being presented with the questions in a different order or getting slightly different questions and the numbers within individual questions also being randomly generated. Other students in the class are too busy with their own work to help a student sitting an assessment, and there is always a tutor present to check on progress. Also a classical way of cheating is to know what the questions are beforehand, but the students know the type of question being tested anyway because they are tackling the tests as tutorials first, so that method of cheating does not arise. Students also sit assessments on the various topics at different times and this reduces the scope for cheating. Students must inform the tutor if they are to sit an assessment and the background colour of the screen changes from green to blue when the tests are attempted as an assessment. The tutor can see immediately who is sitting a tutorial or assessment.

Students pointed out what they felt to be other drawbacks, such as by working at their own pace and being at different stages, it was more difficult for the teaching assistant/lecturer to switch from one topic to the next rapidly when help was required. This was a student perception and not necessarily agreed with by the lecturer.

Also, at present, TASMAT only marks the final answer, not the working as a lecturer would in a traditional exam. This has been addressed by requiring students to use workbooks during the assessments and to keep a record of their working. If a student feels that their work is worth some marks for effort, e.g. they made a silly mistake, the lecturer can check the working and give marks for that. This has been done on several occasions but requires much less effort than marking an exam script and takes place during class time.

Completion rate had been highlighted as a problem in the previous year, so during the second year of running the assessments we were careful to make sure that students were not left behind and they were constantly prompted to keep doing the assessments. A number of students still did not complete on time. This is an unexpected problem for which we have yet to find a solution.

Towards the end of the first session of running CAA, a serious system crash left the server out of action for a week, so that it was impossible for those students who had not completed their assessments by then, to complete them before the end of the year. These students had to be given extra time.

\section{CONCLUSIONS}

Being aware that students now enter higher education with a reduced basic mathematical capability, to what was expected even 10 or 15 years ago, has prompted a change in delivery and assessment to a mathematics course specifically designed for students entering a technological education degree. CAL had already been introduced for content delivery 5 years earlier and using CAA facilitated the reorganisation of the assessment procedure. From the evaluation of its introduction, the following conclusions can be drawn:- 
- $\quad$ Setting a large number of small tests allows all areas of the curriculum to be assessed and using CAA to do this allows it to be done requiring the least amount of effort for most gain financially.

- Students are enabled to learn and complete the assessments at their own pace.

- Students appreciate being able to do the assessments at their own pace.

- Allowing students to work and be assessed at their own pace broadens access to the course for students with more diverse qualifications and also improves the retention rate.

- Broadening access and improving retention rate increases income into the university.

- Students perceive this method of assessment as stress free and also feel that are learning much more, which increases their confidence in the subject.

- The assessments can be used as tutorials first, thus reducing the time staff have to spend on running tutorials.

- Using the computer for the tutorials and assessments releases a considerable amount of staff time that can be used in more productive ways.

- Students need to be constantly reminded that they need to complete all their assessments by a deadline.

Changing to CAA for this course was easy, and also the obvious next step, as CAL was already being used as the predominant course content delivery mode, but it was driven by the desire to change the assessment.

This single innovation, that addressed a specific issue of curriculum coverage, has brought other tremendous benefits such as allowing students on to the course without having the prerequisite qualifications and thus increasing student numbers. Many applicants have other very useful skills to offer the teaching profession, such as industrial experience, craft and drawing skills, and this method of assessment is particularly beneficial for offering access to mature students. By allowing students to work and also be assessed at their own pace the stress of the final examination has been removed and as a result student retention has also improved. It has reduced staff time required for assessment whilst allowing staff to increase the range of assessment.

Introduction of CAA into Higher Education courses could be considered, even for only part of a course assessment, as the benefits may often outweigh any extra effort required in implementing it, and as this case study shows, the implementation may take less time than the original assessment procedure. Using CAA for numerate subjects such as mathematics, science, engineering and technology may be an obvious way forward, but it is also being used in more diverse subjects such as geology and English. Hints for question design in a variety of subjects may be found in the Blueprint for Computer-assisted Assessment (Bull and McKenna 2001).

This course is not static and is reviewed every year for relevance of content and student's learning outcomes, to enable the students to develop their mathematical skills in the best possible way.

\section{REFERENCES}

Booth, D.J.: 1998, "Managing Mathematics with CALMAT", Maths\&Stats 9 (3). 
Brisk, M.L.: 1998, “RE³=X: Re-Engineering Engineering Education”, Global Journal of Engineering Education 2(1), 17-20.

Bull, J., McKenna, C.: 2001, ’Blueprint for Computer-assisted Assessment”, CAA Centre, University of Luton, ISBN 1-904020-003.

CALMAT: 2002, “Mathematics Courseware”, URL: http://www.maths.gcal.ac.uk/calmat/ (April 2002)

Cook, J.: 1994, "Bridge the Gap with CALMAT", in Proceedings of the 7th International Conference on Technology in Collegiate Mathematics, Addison Wesley, 93-96, IBSN-0-20187020-7.

Cook, J., Hornby, J.: 1995, “CALMAT Mathematics Courseware for Access to Higher Education", in Proceedings of the Scottish Mathematics Council Conference, Stirling, Journal 25, $55-57$.

Cook, J.: 1997, “Basic Mathematical Skills: are they important?”, Matematik 19 (2), Malaysian Mathematical Society, ISBN 0126/9003.

Cox, W: 1997, "The challenges faced by students and staff in the transition to first year mathematics at university", in the Institution of Electrical Engineers Colloquium on Teaching of Mathematics for Engineering 4,1-2.

Croft, A.:2002, “The Mathematics Learning Support Centre”, Loughborough University, URL: http://www.lboro.ac.uk/departments/ma/mlsc/oldindex.html (April 2002)

Doughty, G.F., Pollock, M.J., McAteer, E., Turner, I.: 1997, “Conversion of a mathematics course to tutor-supported computer-assisted flexible learning”, in S Brown (ed), Open \& Distance Learning in Industry and Education, Kogan Page, 8, 99-110.

Doughty, G.F., Pollock, M.: 1998, "Evaluating investments in learning technology for Electronics and Mathematics", in of the Proceedings 2nd UICEE Annual Conference on Engineering Education, Auckland, New Zealand.

Doughty, G.: 2002, "Brief guide to the Bachelor of Technological Education degree" URL: http://www.elec.gla.ac.uk/BTECHED/guide/index.html (April 2002)

Evens, H., McCormick, R.: 1996, “The Use of Mathematics in Secondary School D\&T”, BERA (British Education Research Association) Conference September 1996.

URL: http://www.leeds.ac.uk/educol/documents/000000808.htm (April 2002).

Engineering Council: 2000, "Measuring the Mathematics Problem", The Engineering Council, London.

Larcombe, P.J.: 1998, "Engineering mathematics: the crisis continues", Engineering, Science and Education Journal 7 (6), 273-281. 
Lawson, D.: 2000, "Vocational education as preparation for university engineering mathematics", Engineering, Science and Education Journal 9 (2), 89-92.

London Mathematical Society: 1995, “Tackling the Mathematics Problem”, London, Mathematical Society, ISBN 0704416247.

McCormick, R., Murphy, P.: 1996, “The Use of Mathematics in Science and Technology Education; Perspectives and Issues”, BERA (British Education Research Association)

Conference September 1996.

URL: http://www.leeds.ac.uk/educol/documents/000000807.htm (April 2002)

Otung, I.E.: 2001, "Reassessing the mathematics content of engineering education", Engineering, Science and Education Journal 10 (4), 130-138.

Pollock, M.J., McAteer, E., Doughty, G.F., Turner, I.: 1996, "Rapid conversion of a mathematics course to CAL: a case study of a large-scale rapid change of resources and organisation", ALT-J $4,28-34$.

Pollock, M.J., Whittington,C.D., Doughty, G.F.: 2000, "Evaluating the costs and benefits of changing to CAA", in Proceedings of the Fourth International Computer Assisted Assessment Conference, Loughborough, 59-68, ISBN 0-9533210-8-8.

RCC: 2002, “ELICT: Evaluation of Learning with Information \& Communication Technology", Robert Clark Centre for Technological Education, URL: http://www.gla.ac.uk/rcc/projects/elict.html (April 2002)

Robertson, I.J.: 1996, “A Scottish perspective on the great mathematics debate”, BERA (British Education Research Association) Conference September 1996.

http://www.leeds.ac.uk/educol/documents/000000129.htm (April 2002)

Robertson, I.J., Meechan, R.C., Clarke, D., Moffat, J.J.S.: 1996, “Assessment of Achievement Programme (Scotland) Report of the Fourth Survey of Mathematics (1994)", AAP Mathematics Project, ISBN 1900743051.

S.A.B.: 1995, "Statistical Annual report, 1995”, Scottish Examination Board.

S.Q.A.: 2000, “Statistical Annual report, 2000”, Scottish Qualifications Authority, in press.

Tabor, J.H.: 1993 "Using CALMAT in "Levelling Up" Teaching”, CTI Mathematics Quarterly Newsletter 4. 